\title{
Temporal window of receptivity and intraspecific variability in the responsiveness to metamorphosis-stimulating cues in the megalopa of a semi-terrestrial crab, Sesarma curacaoense
}

\author{
P. GEBAUER ${ }^{1,2}$, K.A. PASCHKE ${ }^{2}$ and K. ANGER ${ }^{3 *}$ \\ ${ }^{I}$ Centro de Investigaciones I-MAR, Universidad de Los Lagos, Casilla 557 Puerto Montt, Chile \\ ${ }^{2}$ Facultad de Pesquerías y Oceanografia, Universidad Austral de Chile, Casilla 1327, Puerto Montt, Chile \\ ${ }^{3}$ Biologische Anstalt Helgoland, Stiftung Alfred-Wegener-Institut für Polar- und Meeresforschung, \\ 27498 Helgoland, Germany \\ Tel.+49 (4725) 819348; Fax+49 (4725)819369; email: kanger@awi-bremerhaven.de
}

Received 4 April 2005; Accepted 16 June 2005

\begin{abstract}
Summary
The larvae of numerous sessile and several motile marine invertebrate species respond to metamorphosis-stimulating cues, usually chemical signals from their benthic habitat. In three series of experiments (I-III), the megalopa larvae of a semi-terrestrial mangrove crab, Sesarma curacaoense de Man, were exposed for differential periods to adult-conditioned water (ACW), which had previously been found an effective cue. In the first experimental series (Exp. I), ACW was added on successively later days of the moulting cycle, while Exp. II comprised treatments in which the cues were provided from the first day (postmoult) and removed on sucessively later days. In Exp. III, the megalopae were exposed to ACW for 3 days at the beginning, in the middle, or near the end of the moulting cycle (days 1-3, 4-6, and 7-9, respectively). All experimental series also comprised a permanently exposed control group $(\mathrm{C}+)$ and another one kept in complete absence of the cue $\left(\mathrm{C}^{-}\right)$, and all experiments were repeated with larvae originating from three different females (F1-F3 in Exps. I and II; F4-F6 in Exp. III). Both the timing and duration of exposure to $\mathrm{ACW}$ had a significant influence on the duration of development to metamorphosis, indicating an interaction between the extrinsic signal and the intrinsic (hormonal) control of the moulting cycle. While continuously exposed control megalopae $(\mathrm{C}+$ ) required on average $7.6 \pm 0.5$ to $7.7 \pm 0.5 \mathrm{~d}$, those in group $\mathrm{C}-$ delayed their development by about 3-4 d (or on average by 48\%), 7-9 d (119\%), and 5-6 d (61\%), respectively (F1-F3), indicating a great deal of intraspecific variability among hatches. In Exp. I, the cue had to have been added within about the first 6-7 $\mathrm{d}$ to become effective (no significant difference in development time between treatments and control $\mathrm{C}+$ ), while a later addition of $\mathrm{ACW}$ had no more stimulating effect (no difference to $\mathrm{C}-$ ). In Exp. II, metamorphosis was delayed in all treatments when the cue was removed after an initial exposure of less than 4-5 d, while later removal did not significantly reduce the stimulating effect of ACW. Together, the results from these two experimental series suggest that an exposure approximately during days 4-6 of the moulting cycle may be crucial as a temporal window of receptivity for the cue; this period coincides with the transition between intermoult and premoult (stages $\mathrm{C}-\mathrm{D}_{0}$ of Drach's classification system). Its presumable importance as a critical point was confirmed in Exp. III where development time was consistently shortest in megalopae exposed only during days 4-6 of the moulting cycle (no significant difference to control $\mathrm{C}+$ ), while an earlier or later exposure prolonged development to metamorphosis. Intraspecific variability in the responsiveness to
\end{abstract}


ACW was tested by comparing development time in control groups $(\mathrm{C}+, \mathrm{C}-)$ among megalopae from 14 different hatches (including F1-F6). These data showed a significant variability both in the delay due to complete absence of the cue and in the time of development in $\mathrm{C}+$ groups. Twoway ANOVA indicated significant effects of exposure to ACW and of the female, as well as an interaction between these two factors, not only in development time, but also in the extent of individual variability among equally treated sibling larvae (measured as coefficient of variation). Analysis of molt-frequency distributions showed that the cue had a focussing (variabilityreducing) in addition to the accelerating effect. In conclusion, this study showed that the stage of the moulting cycle as well as intraspecific variability within and among hatches must be considered as potentially confounding factors interacting with effects of metamorphosisstimulating cues. The potential evolutionary significance of intraspecific variability in the extent of phenotypic plasticity is discussed in relation to different ecological scenarios.

Key words: Crab, metamorphosis, settlement cues, Sesarmidae, intraspecific variability, phenotypic plasticity

\section{Introduction}

Most marine invertebrates have a complex lifecycle comprising a planktonic larval and a benthic juvenile-adult phase (Thorson, 1950). The ontogenetic transition from a pelagic to a bottom-dwelling lifestyle is in most cases associated with dramatic behavioural and developmental changes, which are generally referred to as settlement and metamorphosis, respectively. While some species may pass spontaneously through these crucial life-history events, following only a genetically fixed and hormonally controlled developmental programme, others also respond to environmental cues that are usually linked to the adult habitat or to the presence of conspecific adults (for recent review, see Forward et al., 2001, Gebauer et al., 2003). When effective external cues are absent, "competent" larvae (i.e., those being physiologically and morphologically prepared for settlement and metamorphosis) may postpone the initiation of these developmental processes, remaining for an additional period in the plankton.

The appearance of such cues, on the other hand, has a stimulating effect on their transition to the benthos. The occurrence of this response depends, first of all, on the perception of the cue; since this signal has mostly a chemical nature, a well developed larval chemoreceptive system is required (Crisp, 1974). Secondly, the larva must be capable of controlling the timing of metamorphic events, which implies phenotypic plasticity in the behavioural and developmental traits of competent larvae, but may produce also costs for later life-history stages (Pechenik, 1990, 1999).

While numerous sessile marine invertebrates, in particular those with special substrate requirements (e.g., most hard-bottom fauna), have been shown to respond to species-specific settlement- and metamorphosis-stimulating cues (Pechenik, 1990), there are only few examples from motile forms such as decapod crustaceans (Gebauer et al., 2003). In contrast to sessile animals, the latter can continue to search for a suitable habitat also after metamorphosis, i.e., during the benthic juvenile and adult phase, so that the larval choice of a "good" habitat for settlement should be less important.

Sesarma curacaoense de Man, a semi-terrestrial crab living in mangrove swamps in the Caribbean region (Abele, 1992), has been shown to delay its metamorphosis for about 3-4 d (or on average by ca. $48 \%$ ) in the absence of odours from conspecific adults, responding in a similar manner (although to a weaker extent) also to chemical signals released by closely related species (Gebauer et al., 2002). The final larval stage of this crab, the megalopa, may thus be considered as a suitable model for the study of responses to metamorphosis-stimulating chemical cues in decapod crustaceans.

A recent study with another grapsoid crab species, Chasmagnathus granulata Dana, has shown that the response of the megalopa may vary greatly during the successive stages of its moulting cycle, suggesting that an early appearance of the cue before or at the transition from the intermoult to the early premoult period (stages $\mathrm{C}-\mathrm{D}_{0}$ in Drach's classification system; Drach, 1939) appears to be important for its effectiveness (Gebauer et al., 2004). Moreover, observations from the same study suggest that there may be a considerable degree of intraspecific variability in the responsiveness of larvae produced by different females, which may imply differential selective advantages of different phenotypes under different microhabitat conditions (Gebauer et al., 2004). However, these response patterns might represent a speciesspecific trait of $C$. granulata rather than a rule for brachyuran or decapod crustacean larvae, in general. Hence, comparative studies with further responsive 
crab species should be necessary to allow for generalizations. In the present experimental laboratory investigation, we used the megalopa stage of $S$. curacaoense as a model to study both moult-cycle-related variation of responsiveness to a metamorphosisstimulating cue as well as the degree of intraspecific variability among larvae produced by various females.

\section{Materials and Methods}

\section{Origin of materials, larval rearing}

Adult S. curacaoense were collected from brackish coastal mangrove swamps in northern Jamaica (Anger, 1995) and transported alive to the Helgoland Marine Biological Station, Germany. Here they were maintained under constant laboratory conditions of $24^{\circ} \mathrm{C}$ and a salinity of $25 \%$ (obtained by diluting filtered natural seawater from the North Sea with deionized tap water; this culture medium is from hereon referred to as "seawater"). Frozen marine isopods (Idotea sp.) and mangrove (Rhizophora mangle, Laguncularia racemosa) leaves were given as food. Zoeae were massreared in 390-ml beakers (maximum 30 larvae per beaker) without aeration, under the same conditions of temperature and salinity, and an artificial 12:12 h light:dark cycle, until they reached the megalopa stage. The culture medium was changed daily, and the larvae were fed with freshly hatched Artemia franciscana nauplii at a density of approximately $10 / \mathrm{ml}$.

\section{Experimental design}

In three series of experiments (Exps. I-III), carried out with larvae from three different females each (F1-F3 in Exps. I and II; F4-F6 in Exp. III), recently moulted megalopae from the same hatch (maximally $12 \mathrm{~h}$ old) were randomly assigned to various treatments or control conditions. Each of these comprised, depending on availability, 10-12 individuals which were distributed among 5-6 replicates (two megalopae each). The larvae were reared in $100-\mathrm{ml} \mathrm{Nunc}^{\mathrm{TM}}$ plastic bowls filled with ca. $80 \mathrm{ml}$ of seawater $(25 \%$ salinity).

In Exp. I, the experimental exposure to a metamorphosis-stimulating cue (adult-conditioned water, ACW; for details, see Gebauer et al., 2002) began in the various treatments on successive days after moulting to the megalopa stage. In Exp. II, the megalopae were from the beginning of the experiments in contact with $\mathrm{ACW}$, but the exposure was in different treatments terminated on successive days. Exp. III comprised three treatments with an exposure to $\mathrm{ACW}$ during an early, intermediate, and late part of the moulting cycle (days 1-3, 4-6, and 7-9, respectively). In addition, each of the three experimental series comprised also one control group which was continually exposed to $\mathrm{ACW}(\mathrm{C}+)$ and a second control $(\mathrm{C}-)$, which was never in contact with the cue.

During the change of water and food, the megalopae were checked daily for mortality and metamorphosis. The time of development in the megalopa stage was used as a quantitative criterion for effects of treatment, i.e., of adding or withdrawing metamorphosis-stimulating cues at different times of the moulting cycle.

\section{Intraspecific variability in responsiveness}

The control groups $(\mathrm{C}+, \mathrm{C}-)$ from these experimental series were compared to evaluate the degree of intraspecific variability in responsiveness of larvae obtained from six different females. These data were complemented with previously published data from two other hatches of $S$. curacaoense (presented as pooled data in Gebauer et al., 2002), and with those from six further hatches (Gebauer, unpubl. data), so that in total materials from 14 females became available for comparison.

\section{Moult staging}

Megalopae sampled from parallel rearing experiments with or without an addition of chemical cues were microscopically checked for the moulting stage using the last pair of pleopods as a reference site (magnification $\times 100$ to $\times 400$; classification after Drach, 1939; for details of its application to larval decapods, see Anger, 2001).

\section{Statistical analyses}

Statistical analyses followed Sokal and Rolf(1995). Effects of different experimental treatments (Exps. IIII, with differential timing of addition or removal, respectively, of the metamorphosis-stimulating cue) were analysed comparing mean durations of the megalopa stage with non-parametric one-way ANOVA (Kruskal-Wallis $H$ tests). Multiple a posteriori comparisons with the control groups $\mathrm{C}+$ and $\mathrm{C}$ - were done using Dunn's test for different sample size. In our study of intraspecific variability in the responsiveness of larvae produced by 14 different females, we analysed data of development duration and coefficients of variation in development time (CV) employing twoway ANOVA to identify effects of females and ACW as factors. Multiple comparisons were subsequently done with Student-Newman-Keuls tests (SNK). Data 
of developmental delay in experimental treatments (compared to development time in permanently exposed control groups, $\mathrm{C}+$ ) were fitted to a sigmoidal model using the least-squares method.

\section{Results}

\section{Effects of successively later beginning exposure to adult odours (Experiment I)}

The duration of the megalopa stage was in all three trials strongly affected by when exposure to odours from conspecific adults was begun (Kruskal-Wallis $H$ tests, $P<0.001$ ). Multiple comparisons (Dunn's tests) consistently revealed two groups of responses: The first one comprised those where the megalopae were exposed to ACW for 1-6 or 1-7 d (larvae from females F1 and F2 or from F3, respectively; see Fig. 1). Mean development duration varied little among the continuously exposed $\mathrm{C}+$ groups $(7.6 \pm 0.5$ to $7.7 \pm 0.5 \mathrm{~d})$, while slightly longer and more variable development times $(8.8 \pm 1.2$ to $10.3 \pm 0.7 \mathrm{~d})$ were observed in this set of treatments (not significantly different from that in control $\mathrm{C}+$ ).

In treatments with later exposure to $\mathrm{ACW}$, the time of development through the megalopa stage was always significantly longer than in the permanently exposed control group $\mathrm{C}+$, but not significantly different from that in the second control, $\mathrm{C}_{-}^{-}$, in which megalopae never came in contact with a metamorphosis-stimulating cue. Development duration varied among these treatments and in $\mathrm{C}$ - controls between $10.2 \pm 1.4$ and $16.4 \pm 0.8 \mathrm{~d}$, without showing a clear pattern (Fig. 1).

\section{Effects of initial, successively later ending exposure to adult odours (Experiment II)}

Also in this experimental series, the duration of the megalopa stage was significantly influenced by the timing of exposure to ACW (Kruskal-Wallis $H$ tests, $P<0.001$; Fig. 2). Again, multiple comparisons consistently revealed two groups of treatments: When the cue was removed within 4-5 d after moulting, the mean time of development to metamorphosis was not significantly different from that in the completely unexposed control group $\mathrm{C}^{-}$. On the other hand, development took under these conditions always significantly longer than in the permanently exposed control, $\mathrm{C}+$.

The second group comprised all treatments where the cue was removed later, after an initial presence for at least 5-6 d (Fig. 2). Here, the duration of development through the megalopa stage did not significantly differ from that in control $\mathrm{C}+$, while it was consistently shorter than in $\mathrm{C}$ - or in treatments with shorter periods of initial exposure.

\section{Summary analysis of Exps. I and II}

When the delay in the time to metamorphosis (quantified as difference between mean megalopal development duration in experimental treatments vs. continuously exposed controls, $\mathrm{C}+$ ) is plotted against the time of initial exposure or absence of adult odours in Exps. I and II, sigmoidal response curves are obtained (Fig. 3). These relationships between the delay ( $y$, days) and the time ( $x$, days) of initial absence (Exp. I) or presence (Exp. II) of the cue can be described with the following equation; the fitted constants $(a, b, c)$, coefficients of determination $\left(r^{2}\right)$, and levels of significance $(P)$ are given in Table 1:

$$
y=a /\left[1+e^{(b-x) / c}\right]
$$

In Exp. I, the delay in metamorphosis remained weak as long as the initial lack of a cue was shorter than about 5-6 d, but it tended to increase in treatments with later beginning exposure to ACW (Fig. 3), indicating that later additions of $\mathrm{ACW}$ had no longer a

Table 1. Sesarma curacaoense, summary analysis of Experiments I and II; $a, b, c$ : fitted constants of sigmoidal response curves (see Fig.3; for model, see text); $R^{2}$ : coefficient of determination; $P$ : level of significance

\begin{tabular}{llllll}
\hline & $a$ & $b$ & $c$ & $r^{2}$ & $P$ \\
\hline Experiment A: & & & & & $<0.05$ \\
$\quad$ Female 1 & 3.7 & 6.4 & 2.2 & 0.92 & $<0.05$ \\
Female 2 & 9.1 & 8.8 & 2.6 & 0.97 & $<0.05$ \\
Female 3 & 4.7 & 6.9 & 1.5 & 0.96 & $<0.05$ \\
Experiment B: & & & & & $<0.05$ \\
Female 1 & 5.3 & 1.9 & -2.4 & 0.97 & $<0.05$ \\
Female 2 & 6.9 & 4.2 & -1.4 & 0.93 & \\
Female 3 & 5.2 & 3.3 & -0.7 & 0.92 & \\
\hline
\end{tabular}



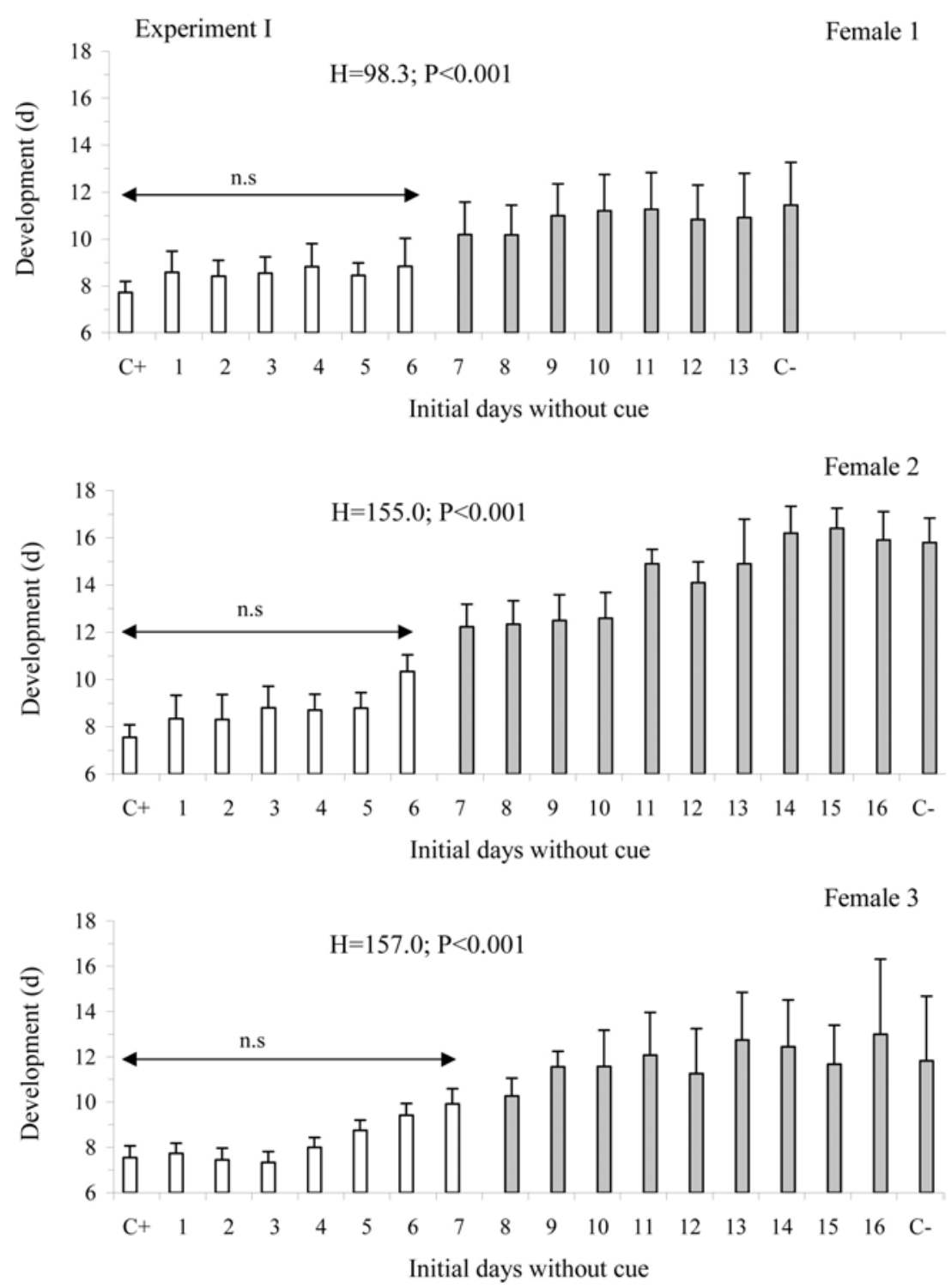

Fig. 1. Duration of development through the megalopa stage (originating from three different females) in relation to differential periods of exposure to a metamorphosis-stimulating cue (adult-conditioned water, ACW), Experiment I: ACW added on successively later days of the moulting cycle, after initial periods without cue; $\mathrm{C}+, \mathrm{C}-$ : control groups exposed continuously to $\mathrm{ACW}$, or never exposed, respectively; H: Kruskal-Wallis statistic indicating a significant treatment effect, level of significance, $P$; open columns: treatments with no statistically significant difference (n.s.) to control group $\mathrm{C}+$ (multiple comparisons with Dunn's tests, $P>0.05$ ), but development significantly shorter than in $\mathrm{C}-$; shaded columns: no significant difference to $\mathrm{C}-$, but development significantly delayed compared to $\mathrm{C}+$.

significant stimulating effect. In Exp. II, short initial periods of exposure $(<4-5 \mathrm{~d})$ had apparently no or only a weak metamorphosis-stimulating effect, while longer periods reduced significantly the delay in megalopal development compared to $\mathrm{C}-$.

Considering both experiments together, it appears that either an initial absence and subsequent exposure to ACW (Exp. I) or the opposite schedule (Exp. II) had, likewise, to include the intermediate period of the moulting cycle (approximately days 4-6 after ecdysis) to exert an effective stimulating effect. This suggests that this time span may represent a crucial temporal window of receptivity for the metamorphosisstimulating cue. Microscopical examination of megalopae reared under identical conditions showed that this period coincided consistently with the transition between stages $\mathrm{C}$ (intermoult) and $\mathrm{D}_{0}$ or $\mathrm{D}_{1}$ (early or intermediate premoult) of the moulting cycle, always including stage $\mathrm{D}_{0}$. 

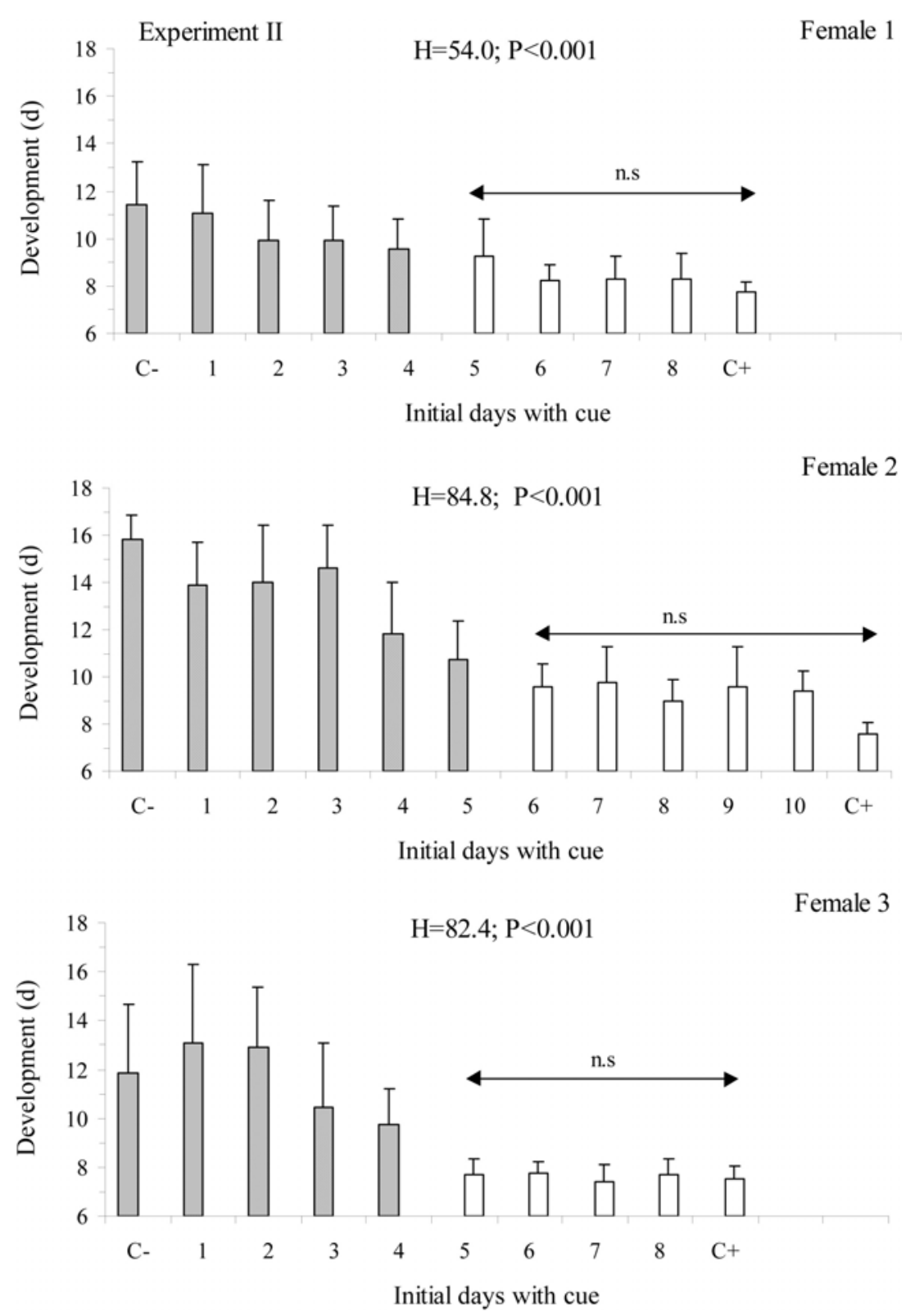

Female 3

Fig. 2. Experiment II: ACW initially present and removed on successively later days of the moulting cycle. For further explanations, see Fig. 1.

Effects of an initial, intermediate, or late exposure (3 days) to adult odours (Experiment III)

In order to test if the period in the middle of the moulting cycle (approximately days 4-6) represents the principal temporal window for maximal effectivity of the cue (see above), we compared in Exp. III the effects of treatments with an initial, intermediate, or final exposure for $3 \mathrm{~d}$ (days 1-3, 4-6, and 7-9, respectively; see Fig. 4). In megalopae obtained from three different females (F4-F6), a significant effect of the timing of exposure was detected (Kruskal-Wallis
$H$ tests, $P<0.001)$. Multiple a posteriori comparisons revealed that development duration was consistently minimum in the treatment with an exposure of 4-6 d (not significantly different from the continuously exposed control, $\mathrm{C}+$, but always significantly different from the unexposed control, $\left.\mathrm{C}^{-}\right)$. An earlier exposure of equal duration (1-3 d) did not prevent a slight but consistent significant delay (Fig. 4). After later exposure (treatment 7-9 d), development duration was intermediate between the two control groups, i.e., not showing a clear effect. The observations of a maximal response to exposure during an intermediate period 
Exp. II: Initial days with cue

Female 1

$\begin{array}{lllllllllllllllllll}0 & 1 & 2 & 3 & 4 & 5 & 6 & 7 & 8 & 9 & 10 & 11 & 12 & 13 & 14 & 15 & 16 & 17 & 18\end{array}$

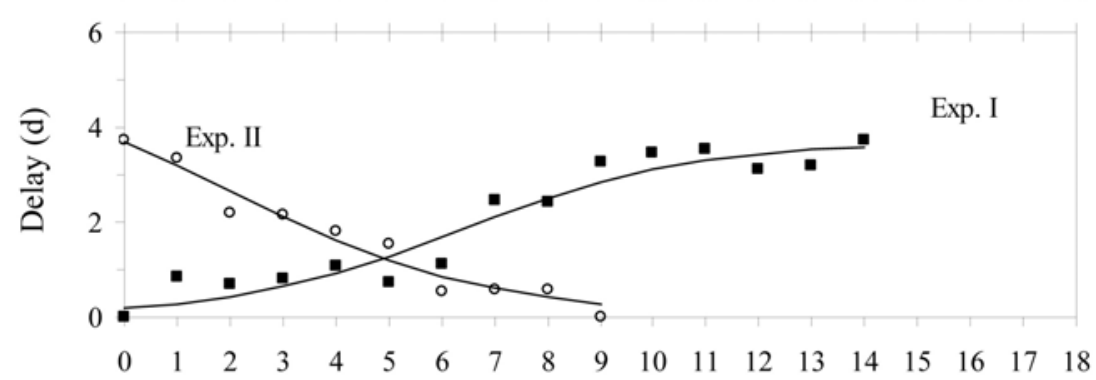

Exp. I: Initial days without cue

Exp. II: Initial days with cue

Female 2

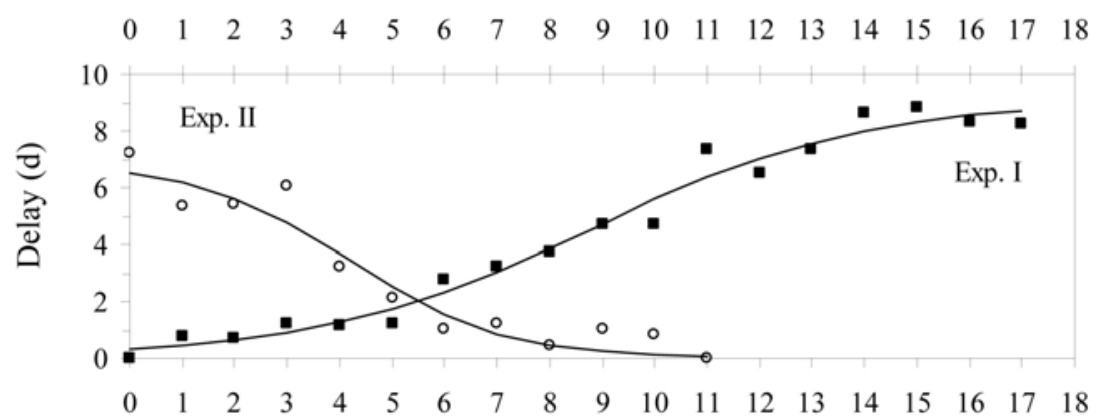

Exp. I: Initial days without cue

Exp. II: Initial days with cue

Female 3

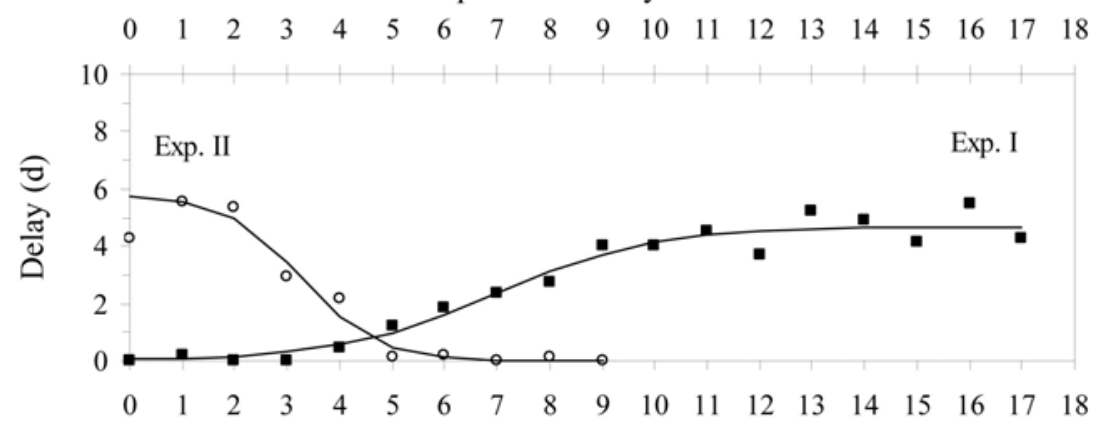

Exp. I: Initial days without cue

Fig. 3. Summary analysis of Experiments I and II (cf. Figs. 1, 2): fitted sigmoidal response curves of developmental delay (days; difference to continuously exposed control, $\mathrm{C}+$ ) in relation to differential periods of exposure to a metamorphosisstimulating cue. For further explanations, see Fig. 1; for model, see text; fitted constants given in Table 1.

within the moulting cycle (4-6 d) corroborate our inference from Exps. I and II that early premoult (stage $\mathrm{D}_{0}$ ) represents a critical point for cue receptivity in the megalopa stage.

\section{Intraspecific variability in responsiveness}

Although the response patterns of the three hatches
(F1-F3) used in Exps. I and II appear to be quite similar, there were conspicuous differences in the extent of the developmental delay due to absence or unsuitable timing of exposure to adult odours (Fig. 3). While the larvae from F1 and F3 showed a maximum delay of about 3-4 or 5-6 d, respectively, those from female 2 delayed their metamorphosis by up to ca. 7$9 \mathrm{~d}$. The theoretical values predicted by the model 

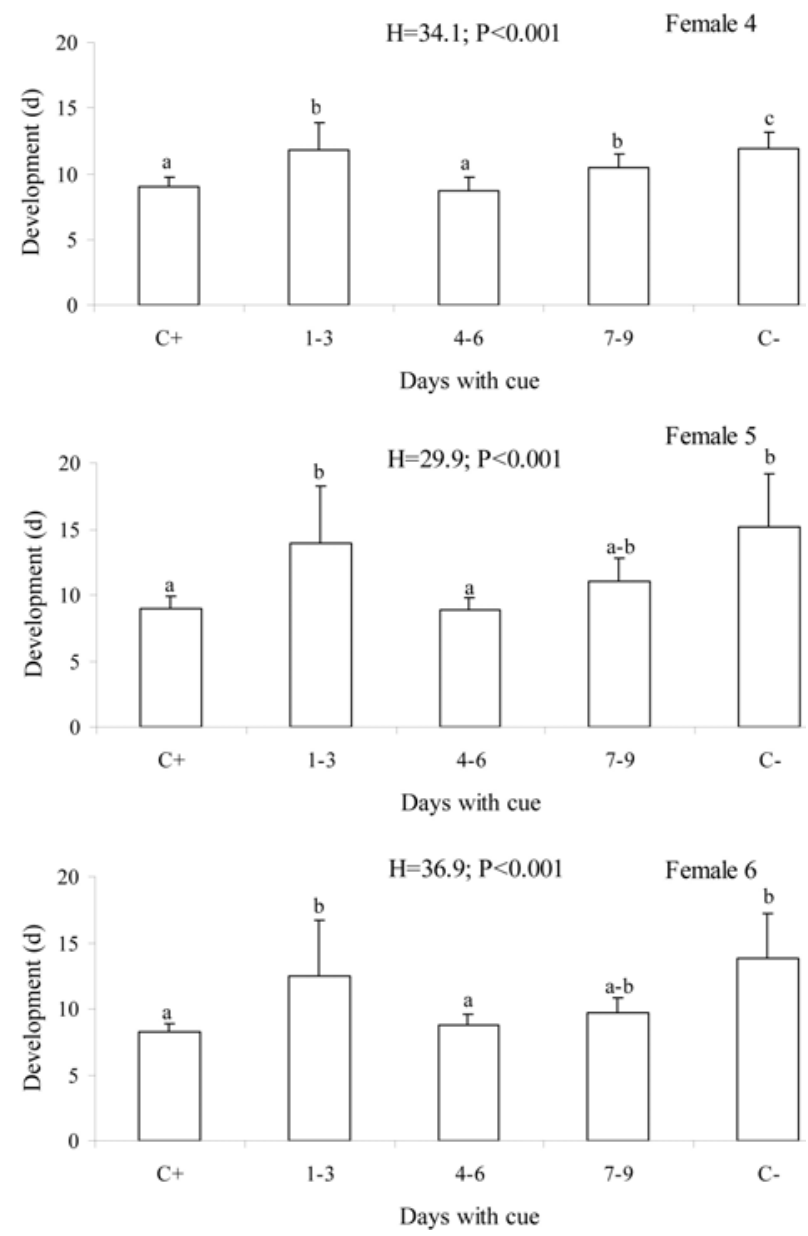

Fig. 4. Experiment III: exposure to ACW for 3 days at the beginning, in the middle, or near the end of the moulting cycle (days 1-3, 4-5, and 7-9, respectively); megalopae originating from three different females, F4-F6; significant differences between treatments or controls $(\mathrm{C}+, \mathrm{C}-)$ indicated by different letters above columns; H: Kruskal-Wallis statistic, with level of significance, $P$. For further explanations, see Fig. 1.

were $3.7 \mathrm{~d}$ in $\mathrm{F} 1$ (or $48 \%$ delay compared to minimum development time under continuous exposure), $9.1 \mathrm{~d}$ (119\%) in F2, and $4.7 \mathrm{~d}(61 \%)$ in F3, respectively, also indicating a great deal of intraspecific variability in the responsiveness to adult odours as a stimulating cue. Similar variability was observed in Exp. III (Fig. 4).

In order to explore the intraspecific variability in responsiveness further, we analysed the development data from 14 different hatches (F1-F14; Fig. 5A; Table 2A). Two-way ANOVA confirmed that both the presence of odours from conspecific adults and the female of origin (or hatch) had highly significant effects on development duration. Moreover, there was a significant interaction between these two factors, indicating that the extent of a delay in absence of a cue, i.e., the degree of phenotypic plasticity in megalopal development duration, differed significantly among hatches. Multiple a posteriori comparisons (SNK) revealed that only one out of 14 hatches (F9) did not show a statistically significant response to the cue (Fig. 5A). In addition to variability in the developmental delay in complete absence of $\mathrm{ACW}\left(\mathrm{C}^{-}\right)$, there was also significant variability among continuously exposed control megalopae from these hatches $(\mathrm{C}+)$.

Our observations of effects of metamorphosisstimulating cues suggested an increase not only in the mean duration of megalopal development in the absence of a cue, but also in the degree of developmental variability among equally treated sibling larvae (cf. Figs. 1 and 2). We explored this apparent effect by comparing the $\mathrm{CV}$ for development time in the same 14 hatches (Fig. 5B). As in the mean values of development duration, two-way ANOVA detected also in the $\mathrm{CV}$ values significant effects of both an exposure to ACW and of the female, as well as an interaction between these two factors (Table 2B). Multiple $a$ posteriori comparisons (SNK) showed in megalopae from 11 out of 14 hatches a significantly stronger degree of variability when they were reared in complete absence of a stimulating cue (only exceptions: F2, F4, F7; see Fig. 5B). This effect also became visible when $\mathrm{CV}$ values for individual treatments or controls of Exps. I and II were plotted against the timing and duration of exposure to ACW (as in Figs. 1 and 2; not shown here). In two out of three hatches (F1, F3; in F2 statistically not significant), the CV showed the same patterns of variation, with the same statistical grouping of treatments in relation to the moulting cycle, as the mean values of development time (see Figs. 1 and 2).

In order to analyse the patterns of developmental variation further in exposed vs. unexposed megalopae, we pooled the data from three females (F2, F5, F6), which all showed a significant developmental delay in the absence of ACW, but no significant femalespecific differences in development duration comparing $\mathrm{C}+$ or $\mathrm{C}-$ groups separately (two-way ANOVA and subsequent SNK tests); in this way, we increased the number of observations to $n=33$ and $n=32$ in groups $\mathrm{C}+$ and $\mathrm{C}_{-}$, respectively, allowing for comparison of frequency distributions. When the number of metamorphic moults per day is plotted against the time within the moulting cycle, it can be seen that the presence or absence of a cue caused not only a shift of the moult-frequency distributions (with little overlap of $\mathrm{C}+$ and $\mathrm{C}-$ data, only on day 10 ), but also a skewness to the right (Fig. 6), explaining the increase in both the mean and $\mathrm{CV}$ values. In conclusion, this analysis revealed that adult odours had both an accelerating and 

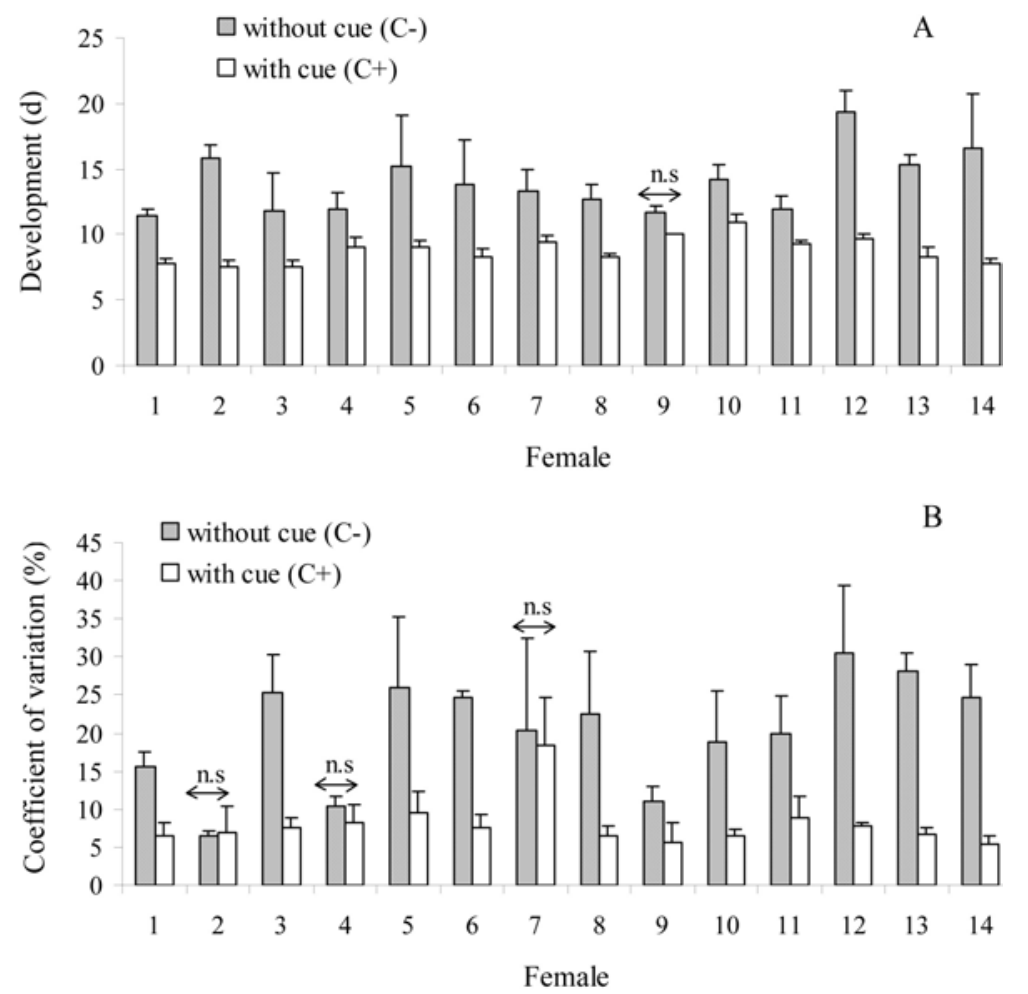

Fig. 5. Intraspecific variability in responsiveness of megalopae obtained from different females (F1-F14) continuously exposed to or kept in complete absence of ACW (control conditions $\mathrm{C}+, \mathrm{C}_{-}^{-}$, respectively; cf. Fig. 1). Upper graph (A): variability in development duration (days). Lower graph (B): variability in the coefficient of variation, CV. n.s.: no statistically significant difference between $\mathrm{C}+$ and $\mathrm{C}-$ (Student-Newman-Keuls test).

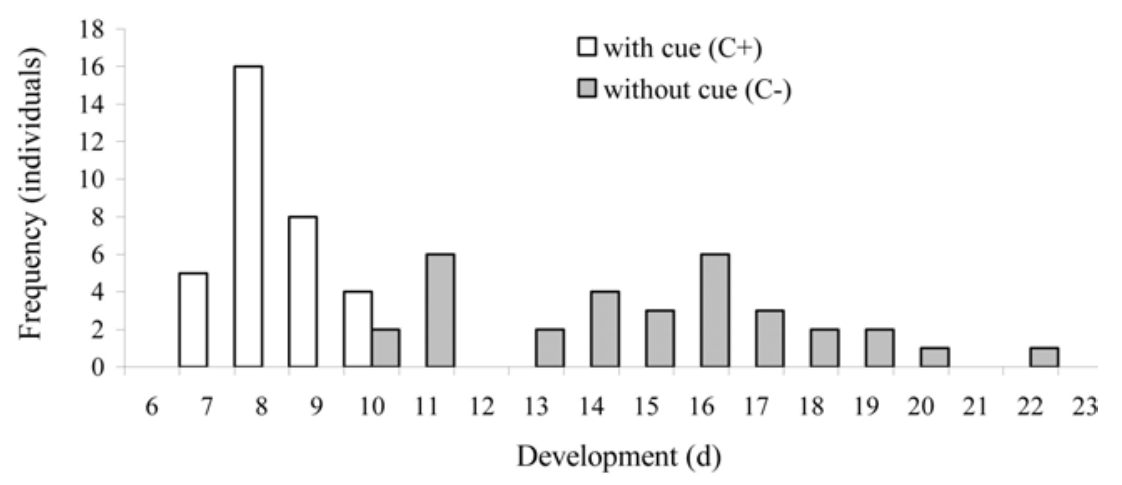

Fig. 6. Moult-frequency distribution of megalopae continuously exposed to or kept in complete absence of ACW (control conditions $\mathrm{C}+, \mathrm{C}-$, respectively; cf. Fig. 1. Pooled data from females F2, F5, F6).

a focussing (i.e., variability-reducing) effect on the temporal pattern of moulting.

\section{Discussion}

This study confirms previous experimental observations (Gebauer et al., 2002) which had shown that the duration of the megalopa stage of $S$. curacaoense is significantly prolonged when stimulating chemical cues from adult odours are absent near the time of metamorphosis. Hence, this semi-terrestrial crab species living in brackish Caribbean mangrove swamps appears to be a suitable model for studies of phenotypic plasticity in the larval development of brachyuran crabs, or decapod crustaceans, in general.

Our present data also correspond with recent observations from another grapsoid crab, Chasmagnathus granulata, where similar experiments had shown interacting effects of the moulting cycle (Gebauer et al., 2004). In both species, an initial or final exposure to 
Table 2. Two way ANOVA showing intraspecific variability among megalopae from 14 different females (see Fig. 5). (A) in duration of development (days). (B) in the coefficient of variation for development duration. DF: degrees of freedom; F: $F$ statistic; $P$ : level of significance

\begin{tabular}{lrcccc}
\hline Source of variation & $D F$ & Sum of squares & Mean squares & $F$ & $P$ \\
\hline A: & & & & & \\
$\quad$ Female & 13 & 169.8 & 13.1 & 7.57 & $<0.0001$ \\
Cue & 1 & 793.7 & 793.7 & 459.87 & $<0.0001$ \\
Female $\times$ cue & 13 & 162.8 & 12.5 & 7.26 & $<0.0001$ \\
Residual & 102 & 176.1 & 1.7 & & \\
$\quad$ Total & 129 & $1,429.5$ & 11.1 & & $<0.0001$ \\
B: & 13 & 1,852 & & 6.33 & $<0.0001$ \\
Female & 1 & $4,432.9$ & $4,432.9$ & 197.1 & \\
Cue & 13 & $1,803.9$ & 138.8 & 6.17 & \\
Female $\times$ cue & 102 & $2,294.1$ & 22.5 & & \\
Residual & 129 & $10,583.5$ & 82 & & \\
Total & & & & & \\
\hline
\end{tabular}

ACW had a stimulating effect only, when the cue was present long enough to include the transitional period between the intermoult and premoult stages of the moulting cycle (stages $\mathrm{C}-\mathrm{D}_{0}$ of Drach's classification system; see Drach, 1939, Anger, 2001). Exp. III confirmed that megalopal responsiveness to the cue was absent or very weak during the initial phases of the moulting cycle (postmoult, intermoult), maximum during early premoult $\left(D_{0}\right)$, and gradually decreasing thereafter (later premoult stages; cf. Fig. 4). This response pattern resembles the "Point of reserve saturation" or " $\mathrm{D}_{0}$ threshold" (see Anger, 2001), where a larva becomes in principle independent from food for the rest of the moulting cycle.

Our observations suggest that endocrine (i.e., intrinsic) control processes such as the production of moulting hormones at the onset of premoult (see Spindler and Anger, 1986) interact with extrinsic factors such as odours from conspecific adults or availability of food. It appears that stage D of the moulting cycle is a largely autonomous sequence of developmental changes that, once it is hormonally initiated, cannot easily be interrupted by extrinsic factors. Future investigations may explore this presumable relationship in more detail, also measuring changes in ecdysteroid titers and/or in the neuroendocrine activity of the eye-stalk complex. The universal occurrence of the same moult-cycle controlling endocrine system in larval and adult decapods (for review, see Chang, 1995; Anger, 2001) renders it likely that similar interactions may also modify the response to metamorphosis-stimulating cues in other crustacean larvae.

Observations of larval salinity tolerance (Anger and Schultze, 1995, Schuh, 1995, Anger and Charmantier,
2000) suggest that $S$. curacaoense follows a strategy of larval retention, or maybe a limited export of its zoeal stages to brackish estuarine mangrove waters, but probably no larval transport to coastal marine waters. This implies that the larvae should pass through their complete development from hatching to metamorphosis in the adult habitat or near to it. The stimulation of metamorphosis by adult odours seems thus not to be absolutely necessary for the larvae to find a suitable type of habitat for settlement, which raises the question what kind of selection pressure may have lead to the evolution of responsiveness to chemical cues. The ecology of this species suggests that it may be associated with its gregarious distribution in the field (Schuh, 1995). Megalopal settlement and metamorphosis in the closest neighbourhood to already existing adult populations, i.e., most likely in a habitat allowing for successful juvenile growth, may enhance the postsettlement survival of early juvenile crabs in an extremely patchy and physically structured semiterrestrial environment where tidal creeks, mud flats, small ephemeral water bodies, trunks and roots of mangrove trees, decaying leaves, and other microhabitats cause conspicuous small-scale variability in physicochemical conditions and in predation pressure.

While the response to adult odours should increase the chance to find the most suitable microhabitat, the selective advantage of this larval behaviour might be offset by increasing cannibalism among different cohorts of juveniles, in particular in physically suitable and thus densely populated habitats (see Luppi et al., 2001). Further ecological field studies considering the settlement of megalopae as well as the patterns of microdistribution of early juvenile crab stages in their natural habitat, including refuge utilization and spatial 
segregation of different age groups (see Luppi et al., 2002), would greatly enhance our understanding of life-history evolution in this and other responsive crustacean species.

Our data show that the responsiveness to a metamorphosis-stimulating cue also varies greatly within and among hatches produced by different females. Since other potentially confounding factors such as temperature, salinity, food, and light were the same in all experiments, this variability should be due to variation either in maternal factors (e.g., variation in size, age, nutritional state of the female), and/or based on genetic differences among larvae. Also, average rates of larval feeding and growth may vary individually even under identical rearing conditions, enhancing the variability in larval condition, and this may interact with the responsiveness to metamorphosis-stimulating cues. In future studies it should thus be interesting to quantify also larval ingestion rates. Variability in egg size, initial larval biomass, and subsequent rates of growth and development can be the result of phenotypic plasticity, originating from environmental variation during oogenesis or embryogenesis, and this variability may persist through later ontogenetic stages, modulating the larval response to environmental variables at metamorphosis, as well as subsequent juvenile growth (Giménez et al., 2004).

If variability within and among hatches has a genetical basis, the extent of responsiveness is a heritable trait, and thus, subject to selection pressures from the environment. Since developmental delay confers energetic costs on competent larvae, often resulting in reduced fitness of early juveniles (see Pechenik, 1990, 1999; Gebauer et al., 1999), phenotypes responding to lacking cues with a strong delay in metamorphosis should be favoured in habitats where suitable substrates for successful larval settlement and juvenile growth are rare or very patchy. On the other hand, physically suitable and densely populated habitats with high predation pressure (cf. Luppi et al., 2001, 2002) should select against this flexible but costly life-history trait. This hypothesis can be tested with combined investigations in the field (studying patterns of larval settlement and juvenile distribution in relation to habitat properties) and in the laboratory (testing the responsiveness of offspring originating from different populations). As a consequence of great intraspecific variability in developmental traits, long-term local or regional variation in ecological conditions may lead to segregation and reproductive isolation of various genotypes and, eventually, aid to speciation (Arthur, 2000). This aspect is particularly interesting in the model species of the present study, S. curacaoense, because it is generally considered as the closest extant relative of a clade of limnic and terrestrial species of sesarmid crabs that have radiated in various non-marine habitats on the island of Jamaica (Schubart et al., 1998; Anger and Schubart, 2005). Besides variability in the dependence of metamorphosis on specific habitat characteristics, the larvae of $S$. curacaoense are highly flexible and variable among hatches also in relation to nutritional and physical conditions (Anger, 1995; Schuh and Diesel, 1995; Anger and Charmantier, 2000). Since intraspecific variation in developmental characters is considered as "the origin of evolutionary novelties" (Arthur, 2000), similar traits may have been a crucial predisposition for evolutionary adaptiveness in the ancestral species that gave rise to the radiation of endemic Jamaican sesarmids.

\section{Acknowledgements}

The first autor acknowledges a grant from the Biologische Anstalt Helgoland (BAH); the second author was funded by the Deutscher Akademischer Austauschdienst (DAAD), Bonn, Germany.

\section{References}

Abele, L.G., A review of the grapsid crab genus Sesarma (Crustacea: Decapoda: Grapsidae) in America, with the description of a new genus. Smithsonian Contr. Zool., 527 (1992) 1-60.

Anger, K., Starvation resistance in larvae of a semiterrestrial crab, Sesarma curacaoense (Decapoda: Grapsidae). J. Exp. Mar. Biol. Ecol., 187 (1995) 161-174.

Anger, K., The Biology of Decapod Crustacean Larvae. Crustacean Issues, Vol. 14, A.A. Balkema, Lisse, The Netherlands, 2001.

Anger, K. and Charmantier, G., Ontogeny of osmoregulation and salinity tolerance in a mangrove crab, Sesarma curacaoense (Decapoda: Grapsidae). J. Exp. Mar. Biol. Ecol., 251 (2000) 265-274.

Anger, K. and Schubart, C.D., Experimental evidence of food-independent larval development in endemic Jamaican freshwater-breeding crabs. Physiol. Biochem. Zool., 78 (2005) 246-258.

Anger, K. and Schultze, K., Elemental composition (CHN), growth, and exuvial loss in the larval stages of two semiterrestrial crabs, Sesarma curacaoense and Armases miersii (Decapoda: Grapsidae). Comp. Biochem. Physiol., 111A (1995) 615-623.

Arthur, W., Intraspecific variation in developmental characters: the origin of evolutionary novelties. Am. Zool., 40 (2000) 811-818.

Chang, E.S., Physiological and biochemical changes during the molt cycle in decapod crustaceans: an overview. J. Exp. Mar. Biol. Ecol., 193 (1995) 1-14. 
Crisp, D.J., Factors influencing the settlement of marine invertebrate larvae. In: Grant, P.T. and Mackie, A.M. (eds.), Chemoreception in Marine Organisms, Academic Press, London, 1974, pp. 177-267.

Drach, P., Mue et cycle d'intermue chez les Crustacés décapodes. Annls. Inst. Océanogr., Monaco, 19 (1939) 103-391.

Forward, R.B., Tankersley, R.A. and Rittschof, D., Cues for metamorphosis of brachyuran crabs: an overview. Am. Zool., 41 (2001) 1108-1122.

Gebauer, P., Paschke, K. and Anger, K., Costs of delayed metamorphosis: reduced growth and survival in early juveniles of an estuarine grapsid crab, Chasmagnathus granulata. J. Exp. Mar. Biol. Ecol., 238 (1999) 271-281.

Gebauer, P., Paschke, K. and Anger, K., Metamorphosis in a semiterrestrial crab, Sesarma curacaoense: intra- and interspecific settlement cues from adult odors. J. Exp. Mar. Biol. Ecol., 268 (2002) 1-12.

Gebauer, P., Paschke, K. and Anger, K., Delayed metamorphosis in Decapod Crustaceans: evidence and consequences. Rev. Chil. Hist. Nat., 76 (2003) 169-175.

Gebauer, P., Paschke, K. and Anger, K., Stimulation of metamorphosis in an estuarine crab, Chasmagnathus granulata (Dana, 1851): temporal window of cue receptivity. J. Exp. Mar. Biol. Ecol., 311 (2004) 25-36.

Giménez, L., Anger, K. and Torres, G., Linking life history traits in successive phases of a complex life cyle: effects of larval biomass on early juvenile development in an estuarine crab, Chasmagnathus granulata. Oikos, 104 (2004) 570-580.

Luppi, T.A., Spivak, E.D. and Anger, K., Experimental studies on predation and cannibalism of the settlers of Chasmagnathus granulata and Cyrtograpsus angulatus (Brachyura: Grapsidae). J. Exp. Mar. Biol. Ecol., 265 (2001) 29-48.
Luppi, T.A., Spivak, E.D., Anger, K. and Valero, J.L., Patterns and processes of Chasmagnathus granulata and Cyrtograpsus angulatus (Brachyura: Grapsidae) recruitment in Mar Chiquita Coastal Lagoon, Argentina. Est. Coast. Shelf Sci., 55 (2002) 287-297.

Pechenik, J.A., Delayed metamorphosis by larvae of benthic marine invertebrates: Does it occur? Is there a price to pay? Ophelia, 32 (1990) 63-94.

Pechenik, J.A., On the advantages and disadvantages of larval stages in benthic marine invertebrate life cycles. Mar. Ecol. Prog. Ser., 177 (1999) 269-297.

Schubart, C.D., Diesel, R. and Hedges, S.B., Rapid evolution to terrestrial life in Jamaican crabs. Nature, 393 (1998) 363-365.

Schuh, M., Fortpflanzungsanpassungen bei der Besiedlung des Landes: vergleichende Untersuchungen zur Ökologie, Fortpflanzungsbiologie und Larvenphysiologie der semiterrestrischen Armases und Sesarma Jamaikas (Decapoda, Brachyura, Grapsidae). Dissertation, University of Bielefeld, 1995.

Schuh, M. and Diesel, R., Effects of salinity and starvation on the larval development of Sesarma curacaoense De Man, 1892, a mangrove crab with abbreviated development (Decapoda: Grapsidae). J. Crust. Biol., 15 (1995) 645-654.

Sokal, R.R. and Rohlf, F.J., Biometry. The Principles and Practice of Statistics in Biological Research. Freeman, San Francisco, 1995.

Spindler, K.-D. and Anger, K., Ecdysteroid levels during the larval development of the spider crab Hyas araneus. Gen. Comp. Endocrinol., 64 (1986) 122-128.

Thorson, G., Reproductive and larval ecology of marine bottom invertebrates. Biol. Rev., 25 (1950) 1-45. 